\title{
PROJETO DE COMUNICAÇÃO PARA O INSTITUTO AMA
}

\author{
Francielli de Fátima Andriolli ${ }^{1}$
}

\begin{abstract}
RESUMO
O presente trabalho propõe um plano de comunicação ao Instituto AMA, com o objetivo de disseminar a marca da instituição para a comunidade do bairro Capão da Imbuia, em Curitiba, onde a entidade está localizada, e para os demais bairros da cidade, além de envolver a comunidade local com a entidade, para que conheça o trabalho desenvolvido pelo AMA e participe ativamente de suas atividades como voluntário ou doador.
\end{abstract}

Palavras-chave: Comunicação, Terceiro Setor, Relações Públicas, Instituto AMA.

\begin{abstract}
The main goal of this work is to develop a communication plan to Instituto AMA. Its objective is to disseminate the institutional brand among the communities of Capão da Imbuia neighborhood, in Curitiba, where the institution is located, as well as to disseminate it in other neighborhoods in the city. Moreover, this communication plan aims to conquer the communities' commitment in the AMA's activities, whose members can help the institution by working as volunteers and donors.
\end{abstract}

Keywords: Communication, Third Sector, Public Relations, Instituto AMA.

\section{INTRODUÇÃO}

O objetivo deste artigo é apresentar $\mathrm{O}$ desenvolvimento de um plano de comunicação para divulgar a instituição do terceiro setor AMA ao público externo. Para isso, busca-se disseminar a marca do AMA para um melhor reconhecimento da sociedade e propor condições para que a comunidade da região do bairro Capão da Imbuia, em Curitiba, interaja e participe mais da instituição.

O AMA é responsável por abrigar crianças com doenças crônicas ou crianças que apresentam algum risco social. Os objetivos deste instituto são: 1) ampliar suas instalações; 2) melhorar a assistência às crianças nele abrigadas; 3 ) tornar a marca mais

\footnotetext{
${ }^{1}$ Especialista em Comunicação Empresarial e Institucional pela Universidade Tecnológica Federal do Paraná. 
conhecida. O plano de comunicação destinado a esse projeto foi elaborado a partir dos objetivos estratégicos da instituição. Nesse contexto, acredita-se que a divulgação da marca AMA e das atividades desenvolvidas pelo instituto junto à comunidade local ocasionará aumento no número de doações por pessoas e empresas, além de engajar mais voluntários. Consequentemente, o AMA terá recursos para ampliar suas instalações e melhorar o atendimento às crianças.

Para tanto é indispensável atrair a atenção e a confiança do público-alvo, o que requer habilidade no modo de comunicar e se fazer entender, propondo técnicas de Relações Públicas e ações pontuais de acordo com o perfil dos doadores em potencial, o que provavelmente resultará no aumento das doações, tornando possível o aumento nas fontes de renda da instituição e consequentemente alcançar a meta almejada.

É importante salientar que se trata de uma ONG (organização não governamental), portanto apresenta características específicas que devem ser respeitadas e levadas em consideração ante as ações de comunicação, uma destas é a questão da verba, que é curta e restrita a determinadas áreas.

Reconhecendo o atual momento do terceiro setor no Brasil e no mundo, como organizações que prestam auxílio à sociedade, uma vez que o Estado não mais atende a esta demanda, as ONGs vêm crescendo de modo contínuo ano após ano e já possuem milhares de pessoas auxiliando seus ideais, entre gestores, voluntários, doadores e beneficiados de entidade beneficente.

Diante deste cenário, este projeto tem como problema de comunicação: desenvolver um plano de comunicação para o AMA, de modo que agregue valor à marca, reconhecimento da instituição por parte da comunidade local e aumento de renda. Para tanto, o objetivo geral consiste em desenvolver um plano de comunicação para a instituição. Os objetivos específicos são: disseminar a marca para um melhor reconhecimento dos moradores do bairro Capão da Imbuia e fazer com que a comunidade interaja e participe mais da instituição. Portanto, esse trabalho justifica-se: o investimento em capacitação pessoal, visual e de relacionamento de uma marca pode significar a continuidade ou não da sua existência. Sendo assim, melhorando a identidade visual do AMA, podemos fortalecer a sua marca e agregar valor econômico e social a ela. 


\section{BRIEFING}

O Instituto AMA (Associação Mantenedora de Apoio à Criança de Risco e com Câncer), registrada sob o CNPJ 05.939.404/0001-69, é uma instituição sem fins lucrativos e presta assistência social a crianças especiais (portadoras de hidrocefalia, paralisia cerebral, insuficiência renal, epilepsia, leucemia) e de risco social.

A ideia para o instituto surgiu em 1993, quando a senhora Nesi Poss descobriu ser portadora de câncer no estômago, fez tratamentos quimioterápicos, os quais a enfraqueceram, deixando-a vulnerável. Nesse mesmo ano, a família foi sensibilizada pela situação e resolveram fazer uma promessa: se o câncer fosse curado, seria criada uma instituição como forma de agradecimento. Nos próximos anos, Nesi descobriu que estava curada e partiu em busca da realização da promessa.

A partir disso nasceram os trabalhos voluntários iniciados por Gasparino Seratto, Ezicléia Poss Seratto, Nesi Poss e Cleverson Siqueira, que visitavam famílias carentes da região do bairro Capão da Imbuia. Com o crescimento do trabalho, foi percebida a necessidade de fundar uma associação em que um maior número de crianças pudessem ser atendidas. Em 2 de julho de 2003 fundou-se o AMA, localizado na rua Emma Elvira Biancolini Bini, 33, no Capão da Imbuia, em Curitiba.

Atualmente, atendem 94 crianças de 2 a 10 anos. Destas, 48 são atendidas diariamente no instituto, sendo 30 crianças no período integral, das 7 h30 às $17 \mathrm{~h} 30$, e 18 em contraturno da escola em que estudam na parte da manhã e logo após vão para a instituição almoçar e passar o resto do dia fazendo atividades do colégio e recreação. As outras 46 são pessoas também da região, que procuraram o instituto para realizar cadastro e logo após receber a visita domiciliar de Ezicleia Poss Seratto e de Nensi Poss, que realizam o cadastro das necessidades, como: medicamentos, fraldas, leite e alimentos. Assim, é realizado o cadastro completo, constando o que cada um necessita e mensalmente, todo dia 20, um responsável pela criança vai até o instituto para receber as doações conforme as necessidades cadastradas.

No AMA as crianças são mantidas $100 \%$ com doações. Para ações em curto prazo, o instituto está disposto a investir 3\% de seu orçamento mensal, que no momento é de $\mathrm{R} \$ 17.000,00$, ou seja, para a comunicação será investida a quantia de $\mathrm{R} \$ 510,00$ mensais. Após novos resultados e com maiores rendimentos mensais, o AMA pensa em disponibilizar quantias necessárias para manter o projeto de comunicação em andamento. 
As solicitações de doações são feitas via e-mail, site e telefone, por 6 colaboradoras, que se baseiam pela lista telefônica. São solicitadas diversas doações em dinheiro, medicamentos, alimentos em geral, roupas e fraldas. A média de doação por pessoa é de $\mathrm{R} \$ 5,00$ por mês, não são doadores fixos e costumam doar mais em datas comemorativas. As arrecadações são feitas via depósito ou motoboy. A ação de comunicação que interessa ao instituto é comercial de TV, pois já houve tentativa de realização, mas não obtiveram sucesso por falta de assessoria.

O instituto busca atender todas as necessidades, desde banho, alimentação, fraldas, roupas e medicamentos. A seleção de crianças é realizada por visitas residenciais e encaminhamentos do FAS (Fundação de Assistência Social) de Curitiba. As instalações não comportam maior número de crianças, por esse motivo não conseguem receber mais crianças em período integral no instituto.

A equipe de trabalho é formada por 20 pessoas, dentre elas 12 colaboradores e 8 voluntários, que não são fixos, pois há grande rotatividade de voluntariado. Não existe nenhum planejamento de comunicação e nenhuma verba específica para tal. Atualmente, existem dois meios de comunicação, um deles é o site (www.institutoama.com.br), que contém informações referentes ao instituto: História, Missão, Serviços, Como ajudar, Eventos, Informações sobre câncer, Drogas, Contatos, e é mantido por um voluntário que conforme solicitação atualiza o site. Outro meio de comunicação utilizado é o folder de papel couché com duas dobras, medindo $12 \mathrm{~cm}$ de largura e $10 \mathrm{~cm}$ de altura, contendo informações (desatualizadas) sobre o instituto.

Não existe um relacionamento maior com a comunidade e por isso ela não conhece a instituição. O problema em relação a parceiros é que doam pouco e exigem aparecer em festas supondo patrocínio como se tivesse doado todo o evento. O instituto AMA não tem apoio financeiro de nenhuma esfera governamental. Na última festa de páscoa realizada, houve a participação de funcionários da empresa Sadia, que colaboraram se vestindo de coelho, fazendo desenhos temáticos para as crianças no dia da festa e com doações de cestas de chocolate.

Atualmente, o instituto AMA conta com o seguinte conjunto de Missão, Visão e Valores apresentados abaixo. E para garantir uma comunicação mais eficaz ao instituto AMA, sugere-se a seguinte proposta: 


\begin{tabular}{|l|l|}
\hline \multicolumn{1}{|c|}{ ATUAL } & \multicolumn{1}{|c|}{ PROPOSTA } \\
\hline $\begin{array}{l}\text { MISSÃO: Garantir aos adultos e crianças } \\
\text { com câncer e risco social, uma qualidade } \\
\text { de vida melhor, através dos serviços } \\
\text { ofertados por nossa instituição. }\end{array}$ & $\begin{array}{l}\text { MISSÃO: Garantir atendimento de boa } \\
\text { qualidade a crianças com necessidade } \\
\text { especiais, câncer ou risco social, por meio } \\
\text { dos serviços ofertados por nossa } \\
\text { instituição. }\end{array}$ \\
\hline $\begin{array}{l}\text { VISÃO: Assim, visamos trabalhar com } \\
\text { toda competência, ética, transparência, } \\
\text { solidariedade e trabalho em equipe, o que } \\
\text { faz o AMA crescer cada vez mais. }\end{array}$ & $\begin{array}{l}\text { VISÃO: Adquirir um novo espaço para } \\
\text { ampliação e se tornar referência em } \\
\text { excelência no âmbito social ao } \\
\text { atendimento infantil na demanda regional. }\end{array}$ \\
\hline $\begin{array}{l}\text { VALORES: Presta assistência emocional } \\
\text { e social, desenvolve um trabalho de } \\
\text { melhoria na qualidade de vida de todos os } \\
\text { nossos assistidos. }\end{array}$ & $\begin{array}{l}\text { VALORES: Trabalhamos com toda } \\
\text { competência, ética, transparência, } \\
\text { solidariedade e trabalho em equipe, } \\
\text { desenvolvendo nosso trabalho de forma } \\
\text { eficiente. }\end{array}$ \\
\hline
\end{tabular}

\section{TERCEIRO SETOR}

A comunicação nas organizações do Terceiro Setor auxilia na disseminação de sua causa, para a mobilização social, para a conquista e fidelização de parceiros, para o alinhamento interno e para que se estabeleçam relações entre elas e seus públicos. Atrair a atenção e a confiança de um público requer habilidade no modo de comunicar e se fazer entender. $\mathrm{O}$ investimento em capacitação pessoal, visual e de relacionamento de uma marca pode significar a continuidade ou não da sua existência. Cada estratégia de comunicação elaborada teve como base os meios de comunicação mais relevantes ao público-alvo do instituto AMA. Vale lembrar que, em se tratando de uma ONG, os recursos financeiros são limitados. Neste caso, utilizar da criatividade se valendo das mídias mais relevantes é um recurso imprescindível.

A população está acostumada com organizações privadas com interesse mercadológico ou organizações públicas de finalidade pública (Estado). E o terceiro setor, colocando-se entre elas, representando a iniciativa privada, de pessoas que se organizam com o objetivo de gerar benefício público. Muitos têm sido os desafios que se colocam ao terceiro setor, para que ele possa provar sua validade social, e contribuir com soluções para o atual contexto de agravamento da exclusão social e de esgotamento de recursos naturais. A prática nas organizações da sociedade civil mostra desafios que precisam ser superados. 
A análise desse conjunto de fatores conduz à ideia de que as organizações podem se beneficiar de planejamento e gestão de comunicação, melhorando a qualidade de seus relacionamentos, e para que ocorra essa melhora no instituto AMA, é de extrema importância divulgar a marca para a comunidade local, sendo assim a mesma poderá contribuir com doações, serviço voluntário e até mesmo na divulgação do instituto para outros bairros da cidade de Curitiba.

Conforme a REBRATES (Rede Brasileira do Terceiro Setor), a sociedade é constituída de três âmbitos ou setores: o Primeiro Setor corresponde à emanação da vontade popular, pelo voto, que confere o poder ao governo, o Segundo Setor corresponde à livre iniciativa, que opera o mercado, define a agenda econômica usando o lucro como instrumento, e o Terceiro Setor corresponde às instituições com preocupações e práticas sociais, sem fins lucrativos, que geram bens e serviços de caráter público, tais como: ONGs, instituições religiosas, clubes de serviços, entidades beneficentes, centros sociais, organizações de voluntariado.

A comunicação contribui com a maximização do relacionamento das organizações no meio externo e interno, com diversas finalidades, como buscar novos parceiros e doadores, recrutar voluntários, informar sobre o andamento das atividades, também sobre como estão sendo investidos os recursos recebidos. Levando em consideração seus princípios, objetivos e sua cultura, elabora-se um projeto de comunicação que busque atender as necessidades tanto da organização como de seus públicos.

A importância da comunicação eficaz no Terceiro Setor é grande, como nos outros dois setores. O uso da comunicação faz-se necessário para que se tornem conhecidas as instituições e consigam disseminar a imagem institucional. Por meio dessa imagem, é possível saber o nível do compromisso da ONG com a qualidade e o respeito aos seus colaboradores e consumidores, e o profissional de comunicação deve estar sempre atento as mudanças constantes que ocorrem nesse meio.

A comunicação excelente é a estratégica, a qual colabora nos processos decisórios e na busca de soluções, sendo assim, o gestor da comunicação deve ter um papel estratégico, se quiser mudar o comportamento da organização num todo e conseguir uma boa aceitação do público. 


\title{
2.1. RELAÇÕES PÚBLICAS NO TERCEIRO SETOR
}

Ser o gestor de Responsabilidade Social, ou responsável pela comunicação de instituições do Terceiro Setor, é uma das áreas que o profissional de Relações Públicas está habilitado a fazer, conforme Margarida Kunsch:

\begin{abstract}
O pleno retorno social é conquistado quando os investimentos são assessorados profissionalmente na pesquisa, planejamento, coordenações, execuções e avaliações das atividades sociais. Funções desempenhadas com know-how pelas Relações Públicas que como gestor dos processos comunicacionais garante o fortalecimento das relações da empresas com os seus públicos (2003, p.129).
\end{abstract}

As técnicas de Relações Públicas são facilmente aplicáveis nas ações visando à captação de recursos e no relacionamento das ONGs com alguns de seus públicos, tais como imprensa, poderes públicos, aliados entre outros, trabalhando com responsabilidade no Terceiro Setor, sendo o facilitador. Conforme Kunsch:

No contexto da temática da responsabilidade social das organizações, outro aspecto relevante a considerar é o trabalho que vem sendo desenvolvido pelo Terceiro Setor. As Relações Públicas poderão contribuir no sentido de facilitar as parcerias e as mediações com o primeiro e o segundo setor (2003, p.144).

\section{RESULTADOS DA PESQUISA}

\subsection{METODOLOGIA}

O estudo fez-se necessário para identificar o perfil dos possíveis doadores e saber como procuram informações ou conhecem as ONGs, quais são as mídias que mais utilizam, se costumam fazer doações e o que os motiva para contribuir com uma instituição. Os resultados da pesquisa irão subsidiar o desenvolvimento de um planejamento de comunicação para o Instituto AMA e contribuir para atender os objetivos determinados neste estudo.

A pesquisa foi realizada com base em dados primários, com o intuito de descrever as características de uma população, mediante os objetivos e finalidades desse estudo, dentre eles identificar as atitudes dos entrevistados em relação às ONGs, identificar o perfil dos doadores para que possa ser constatado o real motivo que os leva a realizar as doações, saber o consumo de mídia dos respondentes, para que os meios de comunicação que o AMA utilize sejam os mais adequados à causa e, por fim, avaliar o 
que motiva a população à ajudar uma ONG, para que o instituto possa contar com essa preciosa ferramenta que é a motivação.

Do ponto de vista da abordagem, optou-se por realizar uma pesquisa de natureza descritiva, utilizando o levantamento do tipo survey, com variáveis quantitativas conforme descrito por Malhotra (2001), Cervo; Bervian (1996), Vieira (2002), Mattar (1996), Marconi; Lakatos (1996) e Perin et. al. (2002).

\footnotetext{
O tipo de pesquisa que se classifica como "descritiva", tem por premissa buscar a resolução de problemas melhorando as práticas por meio da observação, análise e descrições objetivas, através de entrevistas com peritos para a padronização de técnicas e validação de conteúdo (THOMAS; NELSON; SILVERMAN, 2007).
}

O questionário conta com sete perguntas fechadas, o público entrevistado foi de homens e mulheres com idade entre 15 a 76 anos, moradores dos seguintes bairros de Curitiba: Vilas Oficinas, Atuba, Cabral e principalmente o bairro Capão da Imbuia. A amostra é não-probabilística e por conveniência, pois participou somente quem estava disposto a responder o questionário.

A aplicação foi realizada por esta pesquisadora. A coleta de dados foi realizada nos finais de semana de outubro a novembro de 2011, visando identificar junto aos respondentes a visão que eles têm das ONGs e a forma que costumam contribuir com essas instituições. O universo da pesquisa é 79, 653, a amostra é 160. Para tanto foram sondados 180 pessoas, validando 160 questionários. Para a tabulação da pesquisa e análise dos dados foi utilizado o software Excel e elaborada uma análise descritiva.

Dos 160 entrevistados, a maioria, ou seja, 26,9\% têm idade entre 21 a 25 anos, 19,4\% têm entre 26 a 30 anos e 15,6\% entre 31 a 35 anos. Em relação ao grau de escolaridade, $26,9 \%$ possuem graduação superior incompleta, $25 \%$ graduação completa e $19,4 \%$ ensino médio completo. Quanto à renda familiar 69,4\% dos entrevistados possuem renda familiar entre 2 a 4 salários mínimos, 13,8 entre 5 a 7 salários e 10,6\% até 1 salário. Ao serem questionados sobre as ONGs que recordam, 5,7\% dos entrevistados lembram-se do Greenpeace.

Quando questionados se já haviam contribuído para alguma instituição de caridade, 41,3\% afirmaram que sim e 51,9\% disseram que não. Dos que afirmaram que já ajudaram uma instituição, 25\% fizeram doação em dinheiro, alguns além da 
contribuição também fizeram outros tipos de ajuda como trabalho voluntário e doação de diversos como: brinquedos, roupas, alimentos e instrumentos musicais.

Dos que responderam que contribuíram com dinheiro, 67,5\% doaram entre $\mathrm{R} \$ 10,00$ a $\mathrm{R} \$ 20,00$ e $15 \%$ já doaram entre $\mathrm{R} \$ 21,00$ a $\mathrm{R} \$ 50,00$. Com relação aos meios que conheceu a ONG para qual fez a doação, o mais citado foi indicação de parentes e amigos com $22,7 \%$ e com $15,2 \%$ ficou sabendo através de campanhas veiculadas na televisão. Dos entrevistados, 33,1\% dizem conhecer alguma ONG situada no bairro Capão da Imbuia, local onde está localizado o Instituto AMA.

Dos respondentes que nunca fizeram nenhuma doação, $12 \%$ afirmam não conhecer qualquer $\mathrm{ONG}$ e 10,8\% disseram ser por falta de interesse. Para 15,6\% o principal motivo para contribuir é ajudar o próximo, 11,3\% disseram que a credibilidade da ONG é um fator importante e 7,5\% acreditam que o principal motivo é conhecer o trabalho que a instituição desenvolve. Quando questionados sobre as mídias que mais utilizam, com $85,6 \%$ a televisão e Internet com $74,4 \%$. Na televisão, o mais assistido pelos respondentes é o jornal com 52,5\% e em seguida a novela com $30 \%$.

Com relação ao rádio a maioria prefere ouvir a Jovem Pan e em seguida a Transamérica. Quase metade dos respondentes leem o jornal Gazeta do Povo impresso, em que preferem buscar informação. A revista Veja é a mais citada pelos pesquisados, com 29,4\%, ficando com apenas 10\%, em segundo lugar, está a revista Exame. Dos usuários da Internet 44,4\% utilizam mais o e-mail e 41,3\% navegam pelos sites.

\subsection{ANÁLISE DOS RESULTADOS}

A partir da análise dos dados percebe-se que o Instituto AMA não é conhecido no próprio bairro onde atua (Capão da Imbuia), por consequência, a região curitibana também não o conhece. Essa falta de popularidade dificulta a angariação de novos doadores e voluntários, o que é de extrema importância para a instituição.

De 160 entrevistados, $40 \%$ já realizaram doações a instituições do terceiro setor, o que demonstra que as pessoas estão dispostas a colaborar com as ONGs, principalmente, conforme resposta ao questionário, instituições relacionadas ao desenvolvimento ambiental, como o Greenpeace, que por sua vez possui diversas ações de comunicação e realizam atividades por muitas vezes polêmicas, conseguindo dessa forma, com que grande parte da população do mundo inteiro conheça o trabalho da ONG. 
Os entrevistados demonstraram que preferem doar dinheiro, entre $\mathrm{R} \$ 10,00$ a $\mathrm{R} \$ 20,00$, o que significa que podem ser feitas campanhas de doações com foco nesses valores. Em segundo lugar a preferência em doações é de diversos, podendo citar brinquedos e outros produtos, o que também pode ser usado para uma campanha.

A indicação de amigos e parentes é o principal meio citado entre os entrevistados que conhecem alguma ONG, isso nos leva a perceber a imensa importância de se divulgar o AMA no bairro de sua localização, para que os moradores possam indicálo aos demais. E também direcionar ações de comunicação às pessoas que já realizaram doações para que estas sejam mensais, e estimular essa população a se envolver mais com a ONG, visitando suas instalações e conhecendo o seu trabalho. Desta forma, pode ser realizado um trabalho para estimulá-las a falarem do AMA para amigos e convidá-los a participar como doadores ou voluntários.

Também é visto que a maioria conhece instituições que não pertencem ao bairro Capão da Imbuia. O fato de não conhecer a ONG é um fator prejudicial a sua rentabilidade, pois $12 \%$ dos entrevistados afirmaram que nunca realizaram uma doação por não conhecer uma instituição beneficente. Os entrevistados demonstraram ter como seu principal motivo de contribuição o fato de ajudar as pessoas, algo que é relevante ao AMA, já que se trata de uma instituição que auxilia ao público infantil.

Para que se soubesse a forma mais adequada de divulgação em mídia, foi questionado qual meio de comunicação faz parte do cotidiano dos entrevistados, que por sua vez, demonstraram interesse por televisão, sendo o jornal o mais assistido, com 52,5\% da preferência. Foi identificado que $74,4 \%$ dos entrevistados fazem uso da internet como fonte de consulta. De modo que, elaborar um site atrativo, de fácil acesso e que seja agradável, permitirá um aumento no número de acessos, e em consequência gerando aumento de doadores. O público que já realiza doações terá, no site da instituição, uma fonte de informação, reconhecendo a transparência nas ações do Instituto.

Outro recurso de mídia sugerido é o uso de um Spot, no qual será possível expor de modo breve e barato a informação para atrair futuros doadores e tornar o instituto AMA mais conhecido no bairro onde está localizado, em Curitiba e região. Esta estratégia foi pensada com base no resultado da pesquisa que demonstra que 57,5\% dos entrevistados ouvem o rádio como recurso de entretenimento e informação. 
Os resultados mostram a necessidade de um plano de comunicação para tornar o Instituto AMA mais conhecido pela população do bairro do Capão da Imbuía e região Curitibana. E, desta forma, conseguir mais doações e auxílio à instituição. Também acredito que se a comunidade local fortalecer a ONG será mais fácil de solicitar apoio ao poder público, principalmente a vereadores do próprio bairro.

\section{REFERÊNCIAS}

MOREIRA, Fabiana M. D. de Campos. Comunicação e Relações Públicas para a Superação dos Desafios do Terceiro Setor. São Paulo: ECA/USP, 2006.

PÚBLIO, Abílio Marcelo. Como planejar e executar uma campanha de propaganda: Atlas, 2002. p.77

CABRAL, Adilson Vaz Filho. A procura de um meio: o papel da comunicação para as ONG's no Brasil. 01/05/1995 1v. 117p. Mestrado. Universidade Metodista de São Paulo.

MARANHÃO, Carlos André Cantisani. Contingências de um diálogo possível: a linguagem da comunicação comunitária a partir da participação social. 01/04/2006 1v. 132p. Mestrado. Universidade do Estado do Rio de Janeiro.

THOMAS, J.R.; NELSON, J.K.; SILVERMAN, S.J. Métodos de pesquisa em atividade física. 5. ed. Porto Alegre: Artmed, 2007. 